\title{
Synthesis, Characterization and Antifungal Activity of Manganese (II) Complex with Schiff Base Derived from Acetylacetone and Leucine
}

\author{
Aishatu Salihu Mohammed, Fatima Abubakar, Abigail Ebi Aye \\ Department of Applied Science, Kaduna Polytechnic, Kaduna, Nigeria \\ Email address: \\ Aishasalihumohammed18@gmail.com (A. S. Mohammed) \\ To cite this article: \\ Aishatu Salihu Mohammed, Fatima Abubakar, Abigail Ebi Aye. Synthesis, Characterization and Antifungal Activity of Manganese (II) \\ Complex with Schiff Base Derived from Acetylacetone and Leucine. American Journal of Nano Research and Applications. \\ Vol. 5, No. 6, 2017, pp. 110-113. doi: 10.11648/j.nano.20170506.15
}

Received: October 20, 2017; Accepted: November 3, 2017; Published: December 22, 2017

\begin{abstract}
This study was aimed at synthesizing, characterizing and evaluating the antifungal activity of the Schiff base and Mn (II) complex. The reaction of the mixture of ethanol solution of acetylacetone and leucine yielded a Schiff base. The interaction between the Schiff base in hot aqueous methanol mixture and manganese (II) chloride in ethanol gave the manganese (II) Schiff base complex. The complex was characterized by decomposition/melting point temperatures, solubility test, IR spectrophotometry, colour determination, dissociation constant of Schiff base and antifungal activity. The Schiff base obtained has yellow colour, with a melting point of $250^{\circ} \mathrm{C}$ and percentage yield of $54.67 \%$ while the manganese (II) complex obtained had a pink colour with decomposition temperature of $167^{\circ} \mathrm{C}$ and percentage yield of $76.40 \%$. The Schiff base and the complex was soluble in some solvents but slightly soluble in others. The Infrared spectra of the Schiff base showed a band at a range of $1600 \mathrm{~cm}^{-1}-1622 \mathrm{~cm}^{-1}$ attributed to $\mathrm{v}(\mathrm{C}=\mathrm{N})$ stretching frequencies establishing it being a Schiff base. Similar bands were observed in the spectra of Manganese (II) Schiff base complex but in lower frequencies indicating that the Schiff base has coordinated to the Mn ion. The antifungal activity of manganese (II) complex showed significant activity on the fungal isolates Candida albican and Sacchromyces cerevisiae. The study concludes that Schiff base synthesized was a weak acid and the Schiff base was not an active drug against the fungal pathogens used but Mn (II) complex was active against the pathogens used.
\end{abstract}

Keywords: Antifungal, C. albican, Infrared, Manganese (II), Schiff Base, S. cerevisiae

\section{Introduction}

Schiff base metal complexes are molecular entity formed by weak association of a central metal ion and a Schiff base. The Schiff base acts as the ligand which surrounds the metal ion/atom to form the complex [1]. They are derivatives of transition metal formed by the condensation reaction [1]. Both Schiff bases and their metal complexes have important applications. They have the ability to coordinate and release ligand in some processes and to oxidize and reduce in other processes making them ideal for use in biological systems. The most common metal used in the body is iron and it plays a central role in almost all living cells e. g. Iron complexes are used in the transport of oxygen in the blood and tissue. Schiff base metal humid acid complex plays important role in the transportation of essential metals or minerals to plants from the soil [2].

The derivatives of leucine and phenylalanine complexes of iron (II) and manganese (II) have essential role in the body as well as inhibiting the growth of microorganism (microbes) e. g. Escherichia coli, Aspergillus flavus etc. Schiff base metal complexes of leucine and phenylalanine are more effective than the parent compound leucine and phenylalanine [3]. Iron and manganese Schiff bases complexes are highly effective anti-inflammatory agents. In addition they have great potentials in the treatment of numerous chronic diseases which includes gastrointestinal ulcer inflammatory disease, epilepsy and diabetes [4]. Schiff base complex of copper (II) 
is useful in the design and manufacture of antiviral materials/drugs which are effective against HIV viruses. It is also helpful in the detection of these viruses in blood samples [5]. Schiff base complex of zinc (II) with L-proline is used in the production of active drug against bacteria such as Bacillus subtilis and positive results have been obtained [6].

Recently in the area of modern medicine, convectional drugs are no longer very effective in the treatment of certain diseases and researches have been conducted to synthesize new drugs that are effective. It is well known that schiff bases and their complexes are active against micro-organisms e. g. fungi, bacteria e. t. c, moreover these compounds are less toxic. Hence this paper was aimed at characterizing and determination of the antifungal activity of manganese (II) complexes with schiff base derived from acetylacetone and leucine.

\section{Materials and Methods}

All reagents used were of analar grade and were used without further purification. All glasswares used in this work were properly washed, rinsed, with distilled water and dried in an oven. Hams constant temperature magnetic stirrer was used for all heating. Kerro Electrical balance model BL3002 was used for weighing. $\mathrm{pH}$ measurements were carried out using Jenway $\mathrm{pH}$ meter model 3305. The Infrared spectral analysis was recorded using the FTIR-8400S Fourier Transform Infrared Spectrophotometer model within the range of $450 \mathrm{~cm}^{-1}-4500 \mathrm{~cm}^{-1}$. Melting pointing and decomposition temperatures were obtained using an electro thermal melting point apparatus. The antifungal screening was performed by Cork borer method. Potato dextrose agar was used as the culture medium. The organisms used were Candida albican and Sacchromyces cerevisiae are both clinical isolates obtained from the Shehu Moh'd Kangiwa Medical Centre's Laboratory.

\subsection{Preparation of Schiff Base}

$1.03 \mathrm{~cm}^{3}$ of $0.01 \mathrm{M}$ acetyl acetone in ethanol $\left(10 \mathrm{~cm}^{3}\right)$ was added to $1.31 \mathrm{~g}$ of stirred solution of leucine $(0.01 \mathrm{M})$ in 20 $\mathrm{cm}^{3}$ of ethanol. The mixture was refluxed for six hours during which the colour of the solution turned to yellow. The resulting solution obtained was evaporated and then refrigerated for crystallization to occur. The crystal was filtered, washed using ethanol, ether and dried in a desiccator [7].

\subsection{Preparation of Mn (II) Complex}

$30 \mathrm{~cm}^{3}$ of the Schiff base in hot aqueous methanol (40:60) was added to the stirred solution of manganese (II) chloride in $25 \mathrm{~cm}^{3}$ of ethanol. The mixture was refluxed for three hours and then cooled to room temperature. On cooling, a colored solid was obtained which was filtered and washed using methanol and ethanol before drying [7].

\subsection{Dissociation Constant of the Schiff Base}

$100 \mathrm{~cm}^{3}$ of $0.2 \mathrm{M} \mathrm{KNO}_{3}$ was added to $90 \mathrm{~cm}^{3}$ of distilled water in a $500 \mathrm{~cm}^{3}$ beaker, then $10 \mathrm{~cm}^{3}$ of $0.4 \mathrm{M}$ of the Schiff base was added and stirred using a magnetic stirrer. $10 \mathrm{~cm}^{3}$ of standardized aqueous solution of $0.48 \mathrm{M} \mathrm{NaOH}$ was added gradually and the corresponding $\mathrm{pH}$ value recorded after each addition. The dissociation constant pka of the Schiff base was then calculated using the equation below [8]:

$$
\mathrm{pKa}=-\log \left[\mathrm{H}^{+}\right]+\log \left[\frac{\mathrm{A}_{\mathrm{tot}}-\left[\mathrm{Na}^{+}\right]+\left[\mathrm{H}^{+}\right]-\left[\mathrm{OH}^{-}\right]}{\left[\mathrm{Na}^{+}\right]+\left[\mathrm{H}^{+}\right]-\left[\mathrm{OH}^{-}\right]}\right]
$$

\subsection{Characterization of Schiff Base and Manganese (II) Complex}

The Schiff base and Manganese (II) complex were characterized by physical and chemical characterization test.

\subsubsection{Color Determination}

The color of the prepared compounds were identified physically [7].

\subsubsection{Solubility Test}

The solubility of the compounds were analysed using the following solvents: distilled water, methanol, ethanol, butanol, benzene, chloroform, and acetone. $0.2 \mathrm{~g}$ each of the prepared compounds were taken in a separate clean test tube and the solvent was added drop-wise then in excess while shaking and then observed for any visible change/reaction [7].

\subsubsection{Melting Point Determination}

Melting point was determined using an electro-thermal melting point apparatus.

\subsubsection{Infrared Spectrum}

The prepared compounds were subjected to IR spectral analysis. The IR spectrum for each compound was obtained using the FTIR-8400S Fourier Transform IR spectrophotometer and the results were recorded [9].

\subsection{Antifungal Activity}

The antifungal activity of the prepared compounds were studied using Candida albican and Sacchromyces cerevisiae. Potatoes dextrose agar was prepared and sterilized. After solidification of the media, holes were bored using a sterilized cork borer and the fungal spore suspension was transferred to the Petri-plates by taking two loopful of the standard inoculums which was evenly streaked on the plates in duplicates. The bored holes were gently filled with $5 \mathrm{mg}$, $10 \mathrm{mg}$ and $15 \mathrm{mg}$ of the Schiff base and Mn (II) complexes solutions and allowed to diffuse into the media. It was incubated at room temperature for 48 hours [8]. Each of the plates was examined for clear zones of inhibition. Diameters of the zone of inhibition was measured with a millimeter rule and recorded in the nearest millimeter [10].

\section{Results and Discussion}

Table 1 shows the physical properties of Schiff base and manganese (II) complex. The synthesized Schiff base was yellow with a melting point of $250^{\circ} \mathrm{C}$ and percentage yield of $54.67 \%$. The manganese (II) Schiff base complex synthesized 
was pink with decomposition temperature of $167^{\circ} \mathrm{C}$. The Schiff base and its metal complex were soluble in methanol, ethanol and chloroform but are slightly soluble in distilled water, acetone and benzene as shown in Table 2. The pka value of the dissociation constant of the Schiff base was 8.68 indicating that the Schiff base is weak acid.

Table 1. Physical properties of the Schiff base and its manganese (II) complex.

\begin{tabular}{lllll}
\hline Compound & \% Yield & Color & Melting Point $\left({ }^{\circ} \mathbf{C}\right)$ & Decomposition Temp. $\left({ }^{\circ} \mathbf{C}\right)$ \\
\hline Schiff base $(\mathrm{L})$ & 54.67 & Yellow & 250 & - \\
{$\left[\mathrm{MnL}_{2}\left(\mathrm{H}_{2} \mathrm{O}\right)_{2}\right]$} & 76.40 & Pink & - & 167 \\
\hline
\end{tabular}

Table 2. Solubility of the Schiff base and its manganese (II) complex.

\begin{tabular}{lllllll}
\hline Compound & Distilled water & Ethanol & Methanol & Acetone & Benzene & Chloroform \\
\hline Schiff base $(\mathrm{L})$ & $\mathrm{SS}$ & $\mathrm{S}$ & $\mathrm{S}$ & $\mathrm{SS}$ & $\mathrm{SS}$ & $\mathrm{S}$ \\
{$\left[\mathrm{MnL}_{2}\left(\mathrm{H}_{2} \mathrm{O}\right)_{2}\right]$} & $\mathrm{SS}$ & $\mathrm{S}$ & $\mathrm{S}$ & $\mathrm{SS}$ & $\mathrm{SS}$ & $\mathrm{S}$ \\
\hline
\end{tabular}

Keys

$\mathrm{S}=$ Soluble:

SS $=$ Slightly Soluble

$\mathrm{L}=$ Ligand

The Infrared spectra of the Schiff base showed a band at $1603.86 \mathrm{~cm}^{-1}$ attributed to $\mathrm{v}(\mathrm{C}=\mathrm{N})$ stretching frequencies as shown in Table 3. Similar bands were observed in the spectra of manganese (II) Schiff base complex but in lower frequencies indicating that the Schiff base has coordinated to the respective metal ions. Other bands in the spectra of the manganese (II) complex in the range 402-430 $\mathrm{cm}^{-1}$ and 654-
$667 \mathrm{~cm}^{-1}$ are assigned to $\mathrm{v}(\mathrm{M}-\mathrm{N})$ and $\mathrm{v}(\mathrm{M}-\mathrm{O})$ vibrational modes respectively confirming the combination of the Schiff base to the respective metal ions. The strong bands at $3427.62 \mathrm{~cm}^{-1}$ and $3391.94 \mathrm{~cm}^{-1}$ are attributed to $\mathrm{v}(\mathrm{O}-\mathrm{H})$ stretching frequencies for coordinated water in the Schiff base and manganese (II) Schiff base complex respectively.

Table 3. The Infrared data of the Schiff base and its metal complexes.

\begin{tabular}{lllll}
\hline Compound & $\mathbf{v}(\mathbf{O}-\mathbf{H})$ & $\mathbf{v}(\mathbf{C}=\mathbf{N})$ & $\mathbf{v}(\mathbf{M}-\mathbf{O})$ & $\mathbf{v}(\mathbf{M}-\mathbf{N})$ \\
\hline Schiff base & $3427.62 \mathrm{~cm}^{-1}$ & $1603.86 \mathrm{~cm}^{-1}$ & - & - \\
{$\left[\mathrm{MnL}_{2}\left(\mathrm{H}_{2} \mathrm{O}\right)_{2}\right]$} & $3409.30 \mathrm{~cm}^{-1}$ & $1621.22 \mathrm{~cm}^{-1}$ & $402.17 \mathrm{~cm}^{-1}$ & $654.85 \mathrm{~cm}^{-1}$ \\
\hline
\end{tabular}

The antifungal activity of the Schiff base and Mn (II) complex was determined and the results obtained is shown in Table 4. The manganese (II) complex showed strong activity on the fungal isolates at medium and high concentrations. All organisms were found to be resistant to the Schiff base at all concentrations. The diameter of inhibition zone for each treatment ranged from $7 \mathrm{~mm}$ to $38 \mathrm{~mm}$.

Table 4. Antifungal activity of the Schiff base and manganese (II) complexes.

\begin{tabular}{lllll}
\hline \multirow{2}{*}{ Test Organism } & Compound & Zone of Inhibition & & $\mathbf{1 5} \mathbf{~ m g}$ \\
\cline { 3 - 5 } & & $\mathbf{5} \mathbf{~ m g}$ & $\mathbf{1 0} \mathbf{~ m g}$ & - \\
\hline \multirow{2}{*}{ Candida albican } & Schiff base & - & - & $22.5 \mathrm{~mm}$ \\
\multirow{2}{*}{ Sacchromyces cerevisiae } & {$\left[\mathrm{MnL}_{2}\left(\mathrm{H}_{2} \mathrm{O}\right)_{2}\right]$} & $7 \mathrm{~mm}$ & $14 \mathrm{~mm}$ & - \\
& Schiff base & - & - & $30 \mathrm{~mm}$ \\
\hline
\end{tabular}

\section{Conclusions}

From the results obtained it can be concluded that the Schiff base and its manganese complex were successfully synthesized due to the Infrared spectra results obtained. It can also be concluded that the Schiff base synthesized was a weak acid due to the value obtained from its dissociation constant determination. Due to result obtained from the antifungal activity, it can be concluded that the Schiff base was not an active drug against the fungal pathogens used but its metal complex was active against the pathogens used.

\section{References}

[1] ZH Chohan, M Arif, ZH Akhtar and ST Claudiu. Synthesis, Characterization and Antimicrobial activity of Cobalt metal complex against multi-resistant bacterial and fungal pathogens. Bioinorganic Chemistry and Applications Journal, 2 (6), 2006, 1-13.

[2] $\mathrm{K}$ David and $\mathrm{H}$ Henderson, Biological history of microorganism. American Journal of Infection Control, 34, 2006. 46-56.

[3] D Jeffery. The remarkable story of a wonder drug. Journal of Aspirin. 25 (3), 2005, 50-98. 
[4] A Kimberly, C Nicholas, C Nathaniel and L Anderson. Substituent effects on Keto-Enol Equilibria using NMR Spectroscopy. Journal of Chemical Education, 88 (10), 2011, $1444-1445$.

[5] PA Vigato and S Tamburini. Schiff base: a review of its properties. Journal of Co-ordination Chemistry, 2 (1), 2004, 17.

[6] F Lebon, N Boggeto and M Lebeca. Metal organic commands a new approach for drug discovery: $\mathrm{N}-1,2,3,6$ - trimethoxy benzamide copper (II) complex as an inhibitor of human immunodeficiency virus protease, Biochemical Pharmacology Journal, 63 (10), 2002, 1863-1873.

[7] OW Salawu, PK Onoja and JF Saleh. Chemical properties of compounds. J. Der Chemical Sinica, 2 (5), 2011, 25.
[8] SW Hassan, RA Umar and M Lawal. Evaluation of antifungal activity of Ficus sycomorus L. (moraceae). Best Journal 3 (2), 2006, 18-25.

[9] J Rosenthal, L Combaret and MR Etzel. Metabolic fate of Leucine: A significant sterol precursor in Adipose tissue and Muscle. American Journal of Physiology, 226 (2), 2008, 411418.

[10] M Ul-Hassan, ZH Chohan, A Scozzafava and CT Supuran. Schiff bases of aromatic and heterocyclic sulfonamides and their metal complexes. Journal of Enzyme Inhibition and Medicinal Chemistry. 19 (3), 2004, 263-267. 